\title{
Factors Associated with Mortality in Patients with Gastric Cancer at a Reference Hospital
}

\author{
Francisca Bruna Arruda Aragão ${ }^{1}$, Gerusinete Rodrigues Bastos dos Santos ${ }^{2}$, \\ Gabrielle Vieira da Silva Brasil ${ }^{3}$, Bruno Carvalho Campelo 4 , Ana Patrícia Fonseca \\ Coelho Galvão ${ }^{5}$, Joelmara Furtados dos Santos Pereira ${ }^{6}$, Rodrigo Rodrigues \\ Vasques $^{7}$, Fábio Vidal de Figueiredo ${ }^{8}$, Ana Mônica Abreu dos Santos de Oliveira', \\ Jaqueline Diniz Pinho ${ }^{10}$, Rodrigo Lopes da Silva ${ }^{11}$
}

\begin{abstract}
${ }^{1}$ Master's Degree in Adult and Child Health from the Federal University of Maranhão (UFMA); São Luís - MA, Brazil. ${ }^{2}$ Master's Degree in Adult and Child Health from the Federal University of Maranhão (UFMA); São Luís - MA, Brazil. ${ }^{3}$ Master's Degree in Adult and Child Health from the Federal University of Maranhão (UFMA); São Luís -MA, Brazil. ${ }^{4}$ Physician by University Ceuma, São Luís - MA, Brazil. ${ }^{5}$ Master's degree in Health and Environment from the Federal University of Maranhão (UFMA); São Luís -MA, Brazil. 'Master's degree of the Graduate Program in Family Health by the Federal University of Maranhão - UFMA, São Luís, MA, Brazil. ${ }^{7}$ Digestive System Surgeon, Tarquínio Lopes Filho Cancer Hospital, São Luís - MA, Brazil. ${ }^{8}$ Radiotherapist physician, Master student in Adult Health (UFMA), São Luís - MA, Brazil. ${ }^{9}$ Physician by University Federal of Pará, Belém, Brazil. ${ }^{10}$ Postgraduate Program in Genetics and Molecular Biology (PPGBM), Federal University of Pará (UFPA), Belém, Brazil. ${ }^{11}$ Oncological Surgeon, Master's degree in Adult and Child Health (UFMA), São Luís - MA, Brazil.
\end{abstract}

\begin{abstract}
Background: Gastric cancer (GC) is the second cause of death by tumor in the world. In Brazil, the survival rate of patients with $\mathrm{GC}$ is only five years, due to the low rates of early diagnosis, with about 10 to $15 \%$ of the cases. Thus, this study aims to evaluate the factors associated with mortality in CG patients treated at a reference hospital. Method: The study was carried out based on the survey of 96 medical records of patients diagnosed with GC, whose analyzed data were: sex, age, educational level, occupation (socioeconomic level), and risk factors, such as smoking, alcohol consumption, family history of cancer, staging and type of treatment adopted, among other variables. Statistical analysis was performed using the Statistical Package for the Social Sciences (SPSS-PC) and Kaplan-Meier for survival analysis. Absolute and relative frequencies were calculated for all variables. Results: The sample consisted mainly of male patients with stable union, brown-colored, who lived in the metropolitan region and presented low schooling. In addition, risk factors such as smoking and alcoholism presented a high prevalence in the sample. Regarding mortality, factors such as arterial hypertension $(p=0.1581)$, diabetes $(p=0.3212)$, and alcohol consumption $(p=0.6704)$ were not associated with increased mortality in this study. Conclusion: The clinical and epidemiological profile of patients with GC presented a low degree of tumor differentiation, with predominance of the mixed or unclassifiable subtype. In addition, the majority of the sample was composed of patients living in the metropolitan region and the main form of treatment adopted was surgical intervention in combination with chemotherapy.
\end{abstract}

Keywords: Gastric Neoplasms- Mortality- Medical Records

Asian Pac J Cancer Care, 4 (3), 65-70

Submission Date: 02/01/2019 Acceptance Date: 04/01/2019

\section{Introduction}

Gastric cancer (GC) is the second most common reason for death due to tumor in the world, being more frequent in individuals over 50 years of age (approximately 65\% of occurrences) [1-2].

In Brazil, where health systems and policies aimed at prevention are lacking, this category of cancer accounted for 14,182 deaths in 2013 [3]. The survival rate of Brazilian patients for gastric cancer is only five years and

Corresponding Author:

Dr. Francisca Bruna Arruda Aragão

Department Master's Degree in Adult and Child Health from the Federal University of Maranhão (UFMA); São Luís - MA, Brazil.

Email: aragao_bruna@hotmail.com 
less than $30 \%$, which is contrary to the rate of countries such as Japan and South Korea, of $60 \%$. This low survival is directly related to the low rates of early diagnosis ( 10 to $15 \%$ of cases), which is essential to increase the chances of cure [4].

According to data from the (Brazilian) National Cancer Institute, the gastric tumor is among the most deadly in Brazil, with the third highest occurrence in men and fifth in women [5]. The incidence of individuals with this disease varies in different Brazilian regions, and its high incidence is related to poor eating habits and poor basic sanitation [6]. In the state of Maranhão, for example, a total of 370 new cases of gastric cancer per 100,000 inhabitants were estimated in 2016. In the city of São Luís, the estimate is around 130 new cases per 100 thousand inhabitants in 2016 [7].

The factors for developing stomach cancer are multivariate and are not fully understood. Some of them may be infection with Helicobacter pylori (considered the main cause of GC); diets with excess processed meat (source of nitrite and nitrate), salt and carbohydrate; high consumption of drugs such as alcohol and tobacco; family members with this category of cancer; presence of other diseases such as intestinal metaplasia and chronic gastritis; advanced age; being male; and low socioeconomic status. On this latter, the lack of basic sanitation and houses very close to each other are disseminating factors of H. pylori [8].

The clinical manifestations of GC depend on the stage at which the disease is diagnosed. In the early stage, $80 \%$ of patients may be asymptomatic; and in other stages, the symptoms may be non-specific [9-10]. About $90 \%$ of GC cases are diagnosed late, leading to poor prognosis [11-12].

The GC prognosis is based mainly on the pathological aspects of staging at diagnosis and is related to the depth of tumor invasion and the presence of metastatic lymph nodes. Thus, the most important indicators of the prognosis of the disease are: the damage to the lymph node groups; the age at diagnosis; and the histological type [13-14].

These characteristics will define the course of treatment. Therefore, the surgical approach for healing purposes, involving gastrectomy and lymphadenectomy, is considered the only intervention capable of prolonging survival [15]. However, surgery is also recommended in the palliation of symptoms in cases of advanced disease that, although having exceeded the possibility of cure, present a formal surgical indication due to hemorrhage or tumor obstruction [16-17].

In view of the above, the present study aims to evaluate the factors associated with mortality in patients with GC living in a region with a high index of this type of neoplasia.

\section{Materials and Methods}

This is a cross-sectional, descriptive and retrospective study based on the medical records of patients diagnosed with GC, attended at the Tarquínio Lopes Filho General
Hospital (Cancer Hospital) in São Luís - MA. All procedures and protocols were approved by the Ethics Committee (Protocol No. 1,756,464).

The present study requested the exemption of the Informed Consent Form (ICF) because it is a postfactum research and does not involve contact with the subjects in any stage of the research, following the ethical aspects contained in Resolution 196/96 of the National Health Council [18].

The inclusion criteria were patients of any age and sex, attended at the Cancer Hospital with a diagnosis of GC and who had undergone oncological (curative or palliative) treatment between the year 2011 and 2016. Patients without the surveyed information available and patients who were undergoing treatment were not included in the study.

A total of 96 medical records of GC patients attended at Cancer Hospital between 2011 and 2016 were randomly selected. Data analyzed were sex, age, educational level, occupation (socioeconomic level) and risk factors such as smoking, ethnicity, family history of cancer, and type of treatment adopted, among other variables.

The data was tabulated in spreadsheet using the Microsoft Office Excel 2007 for Windows program. The Statistical Package for the Social Sciences (SPSS-PC) and the Kaplan-Meier method for survival analysis were used for the statistical analysis. The absolute and relative frequencies (\%) were calculated for all variables.

\section{Results}

In the study, 96 medical records of patients diagnosed with GC in the years 2011 to 2016, attended at the Tarquínio Lopes Filho General Hospital (Cancer Hospital) in São Luís - MA, were analyzed. Data on socioeconomic, demographic and risk factors are shown in Table 1, with the absolute and relative frequency of clinical variables.

In relation to sex, the present study presented a higher prevalence of males, with $61(59.5 \%)$, while females were represented by $35(40.5 \%)$ individuals. The mean age of GC diagnosis ranged from 25 to 60 years, with a higher incidence among people aged 41 to 60 years $(46.2 \%)$. Regarding the patient's age in the hospitalization period for treatment, there was prevalence of people aged 41 to 60 years $(46.9 \%)$.

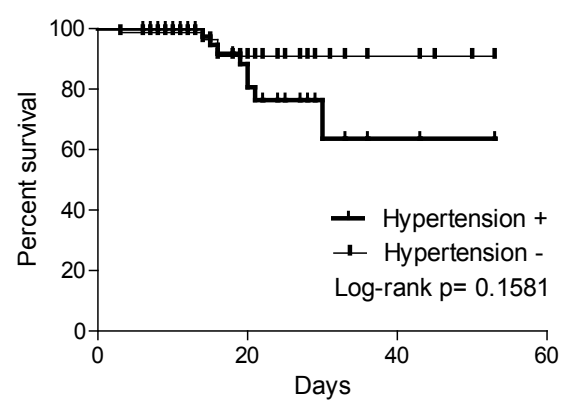

Figure 1. Stratified Survival Curve for Arterial Hypertension 
Table 1. Distribution of GC Patients According to Socioeconomic and Demographic Characteristics and Risk Factors. São Luís, Maranhão, 2017.

\begin{tabular}{|c|c|c|}
\hline Variable & $\mathrm{n}$ & $\%$ \\
\hline \multicolumn{3}{|l|}{ Sex } \\
\hline Male & 61 & 59.5 \\
\hline Female & 35 & 40.5 \\
\hline \multicolumn{3}{|l|}{ Age at diagnosis (years) } \\
\hline Up to 25 & 1 & 1.1 \\
\hline $26-40$ & 7 & 7.5 \\
\hline $41-60$ & 43 & 46.2 \\
\hline Above 60 & 42 & 45.2 \\
\hline \multicolumn{3}{|l|}{ Marital status } \\
\hline Single & 14 & 15.4 \\
\hline Married/Stable Union & 72 & 79.1 \\
\hline Separated/Divorced & 1 & 1.1 \\
\hline Widowed & 4 & 4.4 \\
\hline \multicolumn{3}{|l|}{ Ethnicity } \\
\hline White & 13 & 21.7 \\
\hline Brown & 40 & 66.7 \\
\hline Black & 6 & 10 \\
\hline Yellow & 1 & 1.7 \\
\hline \multicolumn{3}{|l|}{ Origin } \\
\hline Metropolitan region & 53 & 55.2 \\
\hline Interior of Maranhão & 43 & 44.8 \\
\hline \multicolumn{3}{|l|}{ Schooling } \\
\hline Illiterate & 8 & 10.7 \\
\hline Elementary School & 45 & 60.0 \\
\hline High school & 19 & 25.3 \\
\hline Higher education & 3 & 4.0 \\
\hline \multicolumn{3}{|l|}{ Risk factors } \\
\hline Smoking & 36 & 40.0 \\
\hline Alcoholism & 38 & 42.2 \\
\hline Positive H. pylori & 17 & 18.9 \\
\hline Family history of cancer & 29 & 48.3 \\
\hline
\end{tabular}

We observed the predominance of married people/ in stable union, represented by $72(79.1 \%)$ patients. In relation to ethnicity, the brown color was the most prevalent, with $40(66.7 \%)$ patients, followed by the white color, with $13(21.7 \%)$, black color, with $6(10 \%)$, and yellow color, with $1(1.7 \%)$ patient.

Of the analyzed patients, $53(55.2 \%)$ came from the metropolitan region, and $43(44.8 \%)$ lived in the interior of the state of Maranhão. In addition, there was a low level of schooling in this sample. Among the 96 charts analyzed, $45(60 \%)$ were patients who studied until elementary school, 19 (25.3\%) studied until high school, only $3(4 \%)$ were patients with higher education and 8 $(10.7 \%)$ patients were illiterate.

The use of tobacco is a factor closely associated with the presence of $\mathrm{GC}$, being characterized as a risk factor. In the present study, $36(40 \%)$ of the patients reported smoking. Regarding alcohol consumption, 38 (42.2\%)

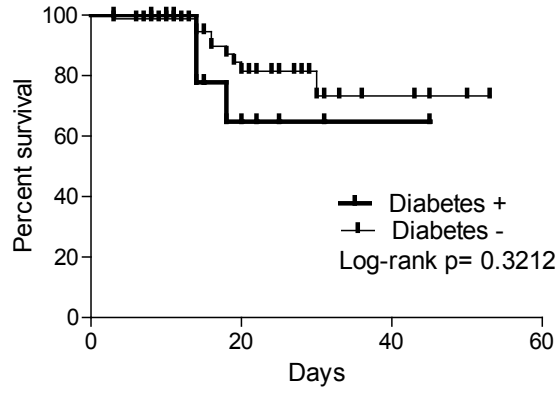

Figure 2. Stratified Survival Curve for Diabetes.

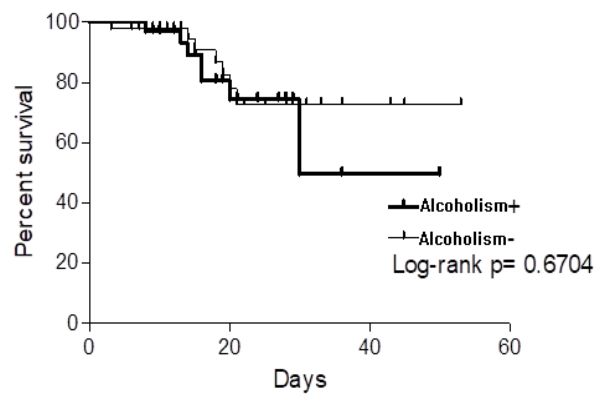

Figure 3. Stratified Survival Curve for Alcoholism.

patients reported consuming alcoholic beverages. H. pylori infection was confirmed in $17(18.9 \%)$ patients, however this information was not available in $79(81.1 \%)$ medical records. On the family history of cancer, 29 (48.3) patients report that there are cases of GC among family members.

Regarding the histopathological characteristics, $29(30.2 \%)$ patients presented initial degree of tumor differentiation, $17(17.7 \%)$ presented the tumor in a moderate state of differentiation, $12(12.5 \%)$ presented the tumor in a well differentiated state and 38 (39.6) patients did not present this information available in their medical records (Table 2).

The most common subtype was mixed or unclassifiable, present in 37 (38.6\%) patients; followed by the diffuse subtype present in $25(26 \%)$ patients; and the intestinal subtype present in $20(20.8 \%)$ patients. Other cancer subtypes were found in 14 (14.6\%) of the medical records.

Regarding the type of treatment performed for $\mathrm{GC}$, according to the analyzed records, $70(73.5 \%)$ patients had undergone surgery, of whom 33 (34.5\%) received adjuvant chemotherapy and $9.6 \%$ chemotherapy and adjuvant radiotherapy. In addition, $15(15.7 \%)$ patients received exclusive chemotherapy, $2(2.3 \%)$ received only chemotherapy and radiotherapy, and $8(8.5 \%)$ patients did not present this information on the medical records (Table 2).

In relation to the survival rate of $\mathrm{GC}$ patients in the period evaluated, factors such as arterial hypertension $(\mathrm{p}=0.1581)$, diabetes $(\mathrm{p}=0.3212)$, and alcoholism $(\mathrm{p}=0.6704)$ were not associated with increased mortality in this study (Figure 1, Figure 2 and Figure 3). 
Table 2. Distribution of GC Patients According to Histopathological Data and Treatment. São Luís, Maranhão, 2017.

\begin{tabular}{lcc}
\hline Variable & $\mathrm{N}$ & $\%$ \\
\hline Degree of differentiation of tumor cells & & \\
$\quad$ Well differentiated & 12 & 12.5 \\
Moderately differentiated & 17 & 17.7 \\
Poorly differentiated & 29 & 30.2 \\
Undifferentiated & 38 & 39.6 \\
Subtype & & \\
Diffuse & 25 & 26.0 \\
Intestinal & 20 & 20.8 \\
Mixed or Unclassifiable & 37 & 38.5 \\
Other types of cancer & 14 & 14.6 \\
Treatment & & \\
Exclusive surgery & 28 & 29.4 \\
Surgery + adjuvant CT & 33 & 34.5 \\
Surgery + adjuvant CTRT & 9 & 9.6 \\
Exclusive CT & 15 & 15.7 \\
CTRT & 2 & 2.3 \\
Ignored & 8 & 8.5 \\
TOTAL & 96 & 100 \\
\hline CT, & &
\end{tabular}

CT, chemotherapy; CTRT, chemotherapy and radiotherapy.

\section{Discussion}

The objective of this study was to evaluate the factors associated with mortality in GC patients treated at a reference hospital in São Luís, Maranhão. The analysis of the information contained in the medical records showed that the sample consisted mainly of male patients, in stable union, brown, living in the metropolitan region and with low educational level. In addition, risk factors such as smoking and alcoholism were found to be highly prevalent in the sample; H. pylori infection was confirmed; and patients report that there are cases of GC among family members.

With regard to age, it was observed that, as in other studies [19-20], the incidence of gastric cancer increases markedly with age. Other studies [21-22] suggest that the individual risk of stomach cancer is established near or below 40 years and that the increase in its incidence occurs predictably after this age.

According to a study [23], the incidence increases progressively with age, with peak incidence between 50 and 70 years. Only $2 \%$ to $9 \%$ of all gastric cancer patients are under 40 years of age. In this way, the incidence of GC increases in adulthood because aging impairs the efficiency of physiological processes and causes the reduction of mechanisms of protection and reparation of the gastric mucosa. Also, the harmful effects of the environmental risk factors become more evident, and one's unfavorable lifestyle changes the cellular processes, resulting in the development and progression of cancer [10].

These results corroborate with the existing scientific literature regarding the predominance of this type of cancer among males [24] consumers of alcohol and tobacco and with low educational level. This aspects are associated with delay of more than 30 days until the first treatment, demonstrating that not only clinical aspects, but also socio-cultural patterns interfere in the search for treatment [25].

In the present study, $38 \%$ of patients diagnosed with GC confirmed to be both alcoholics and smokers. According to a study [2], smoking is an important risk factor for developing GC. Since 2002, the IARC has said there is sufficient evidence of causality between smoking and GC. Other epidemiological studies [25-26] suggest that alcohol plays a key role in carcinogenesis, especially for cancers of the mouth, pharynx, larynx, esophagus and stomach, due to its greater effect on directly exposed tissues during consumption and for having a synergic action with tobacco. The duration of smoking time is also a factor that influences carcinogenesis. Even after interrupting it, the reduction of risk does not seem to be immediate, and ex-smokers are usually at increased risk [27]. In this way, there is evidence that alcohol and tobacco are important risk factors for developing GC.

Most patients in the present study were brown-colored and, in general, those with lower levels of education and low income were the most affected. A study [28] demonstrated that the low socioeconomic level strongly points to a greater risk of developing GC. Disadvantaged social groups tend to have less access to health services. Helicobacter pylori infection was confirmed in $18.9 \%$ of the patients, however, in $60 \%$ the information was not available in the medical record, and it was impossible to conclude whether no survey was done or if the result was negative.

According to the histopathological analyzes and the treatment adopted by the patients, the classification of malignant tumors of the evaluated sample was found to be more prevalently in stage IV (34\%), followed by stages IIA, IB and IA with 11,9 and $8 \%$, respectively. This result is partly explained by the precarious public health practices practiced in relation to gastric cancer in Brazil, where the patients arrive at the hospital with a late diagnosis of the disease and are treated lately, obtaining little chance of cure when compared to the international centers of excellence, such as those located in Japan [28-29]. Another possible explanation is that patients in the early stages are often asymptomatic and therefore the diagnosis is made late in the vast majority of Western countries [30-31].

Regarding the treatment, in the findings of the present study, surgery was mandatory in most patients, of whom about $73.5 \%$ were submitted to some type of procedure. As demonstrated in a study [32], depending on staging of the disease, the main treatment is the surgical one. This is because the main treatment of gastric adenocarcinoma is tumor resection [33] and the type of gastrectomy to be performed will basically depend on the location of the tumor and the desired surgical margin. In proximal tumors, total gastrectomy is performed, whereas in the distal tumors, especially when well differentiated, subtotal 
gastrectomy can be performed [34-35].

Another treatment option is the use of chemotherapy as a neo-adjuvant or adjuvant therapy. In addition to tumor resection, the use of chemotherapeutic agents in $\mathrm{T} 3 / \mathrm{T} 4$ or N1/N2/N3 tumors is currently recommended [35]. In the present study, chemotherapy was present in the treatment of $62.1 \%$ of patients, distributed as adjuvant treatment associated with surgery in $35.5 \%$; as adjuvant treatment associated with surgery and radiotherapy in $9.6 \%$ and as exclusive chemotherapy in $15.7 \%$.

The time of hospitalization to perform the treatment was an average of 26.6 days ( \pm 52.6) for all the patients analyzed. In addition, in the present study, 82 patients had been discharged from hospital and 13 died during this period. Some studies [26-36, 37] state that in many parts of the world, more than $90 \%$ of GC cases are detected in advanced stage. It is worth noting that the present study presented limitations in relation to some variables due to the absence of the information in the selected medical record and/or because the patient was hospitalization. The patients who were being treated for GC were excluded from the analysis.

In conclusion, we conclude that the clinical and epidemiological profile of patients with GC presented, in the majority of cases, a low degree of tumor differentiation, with a predominance of the mixed or unclassifiable subtype, and factors such as hypertension, diabetes and alcoholism did not present association with increased mortality in the present study. In addition, the majority of the sample was composed of patients living in the metropolitan area, and the main form of treatment adopted was the surgical intervention in combination with chemotherapy.

\section{Acknowledgements}

We thank all the medical and administrative staff of Tarquínio Lopes Filho General Hospital for the support and availability during the period of this research.

\section{Funding}

The study was not funded.

\section{References}

1. Globocan 2012: estimated cancer incidence, mortality and prevalence worldwide in 2012. IARC Cancer Bases. 2012: 1-6. p.

2. Silva RD DM. Incidência do carcinoma basocelular e espinocelular em usuários atendidos em um hospital de câncer. 2017; 228-34. p.

3. I. I. Estimativa de cancer no Brasil 2014, :p. 2016.

4. Sales ML GA. Fatores de risco no desenvolvimento de câncer gástrico. 2017; 1-24. p.

5. I. I. Estimativa de cancer no Brasil 2016, :p. 2016.

6. Sales ML, Guimarães AVS. FATORES DE RISCO NO DESENVOLVIMENTO DE CÂNCER GÁSTRICO. Revista Brasileira de Ciências da Vida. 2017;5(1).

7. PP. S. Instituto Nacional de Câncer. 2015.

8. Sekiguchi M OI, Suzuki H, et al. Clinical outcomes and prognostic factors in gastric cancer patients aged $\geq 85$ years undergoing endoscopic submucosal dissection. 2017; . 963-72. p.

9. Subirat Esquivel L GID. Algunas consideraciones actuales sobre el Cáncer Gástrico. 2011; . 400-11. p.

10. Park DJ TN, Yoon C, Yoon SS. Vascular endothelial growth factor a inhibition in gastric cancer.2015; . 33-42. p.

11. Hur H PM, Xuan Y, et al. Quantitative measurement of organic acids in tissues from gastric cancer patients indicates increased glucose metabolism in gastric cancer.2014; . e98581. p.

12. Khedmat H PM, Mashahdian M, Rajabpour MV, Zendehdel K. Prognostic Factors and Survival in Stomach CancerAnalysis of 15 Years of Data from a Referral Hospital in Iran and Evaluation of International Variation. 2011; 178-82. p.

13. Chen S RH, Liu J, et al. . Lymph nodes ratio based nomogram predicts survival of resectable gastric cancer regardless of the number of examined lymph nodes. 2017; 455-85. p.

14. Ajani J BJ, Bekaii-Saab T. NCCN Clinical practice guidelines in oncology. 2010;

15. Sousa MTDd S-RP, Cabral MMDÁ. Impact of using a lymph node revealing solution in surgical specimens for pathological staging of gastric cancer. Jornal Bras Pat Med Labor 2014;;50::445-51.

16. Network. NCC Clinical Practice Guidelines in Oncology: Gastric Cancer Version 3. 2015.

17. Smyth E VM, Allum W, Cunningham D, Cervantes A, Arnold D. Gastric cancer: ESMO Clinical Practice Guidelines for diagnosis, treatment and follow-up. 2016; v38-v49. p.

18. Brasil. Saúde BMd. Conselho Nacional de Saúde. Resolução no 196 de 10 de outubro de 1996. Diretrizes e Normas Regulamentadoras de Pesquisas Envolvendo Seres Humanos: Diário Oficial da União; . 1996.

19. LP. C. Gastric cancer review. Journal of Carc. 2014;13:1-14.

20. Aguiar Jr P SG, Barão K, Forones N. Chemotherapy for elderly patients with gastric cancer: experience of a Brazilian center. 2016; . 71-9. p.

21. Wachtel MS ZY, Chiriva-Internati M, Frezza EE. . Different regression equations relate age to the incidence of Lauren types 1 and 2 stomach cancer in the SEER database: these equations are unaffected by sex or race. 2006; 1-11 p.

22. White MC HD, Boehm JE, Peipins LA et al. Age and cancer risck: a potentially modifiable relastionship. . Am J Prev Med. 2015; ;46::1-16.

23. Zhou F SJ, Fang C, Zou X, Huang Q. Gastric carcinomas in young (younger than 40 years) chinese patients: clinicopathology, family history, and postresection survival.2016; . 1-11. p.

24. Ferlay J SI, Dikshit R, et al. Cancer incidence and mortality worldwide: sources, methods and major patterns in GLOBOCAN 2012. 2015; .

25. Dalla Valle T TR, de Brito Poveda V. Fatores intervenientes para o início do tratamento de pacientes com câncer de estômago e colorretal. 2017; 1-9. p.

26. Valle TD, Turrini RNT, Poveda VB. Intervening factors for the initiation of treatment of patients with stomach and colorectal cancer. Revista latino-americana de enfermagem. 2017;25:e2879.

27. Hu B, El Hajj N, Sittler S, Lammert N, Barnes R, MeloniEhrig A. Gastric cancer: Classification, histology and application of molecular pathology. 2012; 251. p.

28. Araújo Júnior ON AA, Barboza DRMM, Meireles MS, Pinheiro MV, Pinheiro ATM. Perfil epidemiológico e histopatológico do câncer gástrico. 2013; . 26-33. p.

29. Seabra AD AT, Mello FAR, et al. High-density array comparative genomic hybridization detects novel copy number alterations in gastric adenocarcinoma. Antican resear 
2014;34:6405-15.

30. Pirini F NS, Jahuira-Arias MH, et al. Early detection of gastric cancer using global, genome-wide and IRF4, ELMO1, CLIP4 and MSC DNA methylation in endoscopic biopsies. 2017; . 38501-16. p.

31. Andreollo NA LL, Neto C, de Souza J. Complicações pós-operatórias após gastrectomia total no câncer gástrico: análise de 300 doentes. 2011; 126-30. p.

32. Pereira APdS CC, Martins MRI, Pinto MH, Netinho JG. . Associations among socio-demographic and clinical factors and the quality of life of ostomized patients. 2012; .93-100. p.

33. Cóvos FHG FF, Navarro PF, Magalhães P, David WRdFJ, Malheiros CA. . Câncer gástrico avançado: complicação pós operatória-discussão de caso. 2011; 145-9. p.

34. Zilberstein B, Mucerino DR, Yagi OK, Ribeiro-Junior U, Lopasso FP, Bresciani C, et al. Results of D2 gastrectomy for gastric cancer: lymph node chain dissection or multiple node resection? Arquivos brasileiros de cirurgia digestiva : $\mathrm{ABCD}$ $=$ Brazilian archives of digestive surgery. 2012;25(3):161-4.

35. C. M. Estratégias de enfrentamento utilizadas pelos pacientes oncológicos submetidos a cirurgias mutiladoras. Rev Bras Cancerol 2009;55:355-64.

36. Cabral PG MK, Teixeira MCA, dos Santos Fernandes G. . Resposta completa e duradoura em câncer gástrico metastático HER2-positivo. Rev Sau Faciplac. 2016;3:28-32.

37. Colombi S, Baia RdSM. Sistematização da assistência de enfermagem a um paciente de gastrectomia total: relato de experiência. Nursin. 2015;18:986-90.

\section{c) (i) (5)}

This work is licensed under a Creative Commons AttributionNon Commercial 4.0 International License. 